\title{
Desenvolvimento da Aplicação dos Reatores Anaeróbios de Manta de Lodo (UASB) no Brasil
}

\author{
Erickson Alexandre Marques Aguiar Borges'; Ana Silvia Pereira dos Santos \\ \ericksonall@gmail.com
}

1. Universidade do Estado do Rio de Janeiro, Rua São Francisco Xavier, 524, Rio de Janeiro, Brasil.

\section{Histórico do Artigo:}

Recebido: 31 de março de 2017

Aceito: 1 de junho de 2017

Publicado: 5 de janeiro de 2018

Resumo:A disposição inadequada de esgotos no meio ambiente sempre foi motivo de preocupação das sociedades no mundo. Especialmente em países em desenvolvimento, os problemas de disposição e tratamento de esgotos tornam-se ainda mais evidentes. No Brasil, o avanço nos estudos e pesquisas sobre tratamento de esgotos através de sistemas anaeróbios, notadamente os reatores de manta de lodo (UASB), se deu a partir do Projeto PROSAB, em 1999, de onde surgiram pesquisas, artigos, livros e projetos de diversos autores a respeito do tema, tornando-se referência não só para a revisão na NBR 12.209 em 2011, mas também para a implantação de várias estações de tratamento de esgoto de diferentes portes e em diferentes estados, através das suas respectivas companhias de saneamento. Com o objetivo de analisar a evolução e boa aceitação da tecnologia UASB no Brasil, foram avaliadas as alterações na NBR 12.209, os princípios de funcionamento dos reatores UASB e as companhias nacionais de saneamento que utilizam reatores UASB, fundamentais para o desenvolvimento e aceitação da tecnologia no país. Apesar da divergência quanto à nomenclatura pelas companhias de saneamento no Brasil, a sigla UASB continua sendo a mais difundida e utilizada na literatura sobre os reatores de manta de lodo. 0 maior detalhamento nos parâmetros de projeto apresentados na revisão da NBR 12.209 e as estações de tratamento de esgotocom reatores UASB já implantadas e em operação, a exemplo das 186 estações de tratamento, que juntas tem capacidade de tratar $15.366 \mathrm{~L} / \mathrm{s}$, operadas por quatro das principais companhias de saneamento no Brasil, deixam claro como a tecnologia ganhou espaço em definitivo no Brasil.

Palavras-chave:PROSAB, NBR 12.209, Tratamento de esgoto.

\section{Development of the Application of Upflow Anaerobic Sludge Blanket Reactor (UASB) in Brazil}

\begin{abstract}
Inadequate disposal of sewage into the environment has always been a concern of the world's societies. Especially in developing countries, the problems of sewage disposal and treatment become even more evident. In Brazil, advances in studies and research on sewage treatment through anaerobic systems, notably sludge blanket reactors (UASB), took place from the PROSAB Project in 1999, from which research, articles, books and projects of several authors on the subject, becoming reference not only for the revision in NBR 12.209 in 2011, but also for the implementation of several sewage treatment plants of different sizes and in different states, through their respective sanitation companies. In order to analyze the evolution and good acceptance of the UASB technology in Brazil, the changes in NBR 12.209, the operating principles of the UASB reactors and the national sanitation companies using UASB reactors were evaluated, fundamental for the development and acceptance of the technology in the country. Despite the divergence regarding nomenclature by sanitation companies in Brazil, the UASB acronym remains the most widespread and used in the literature on sludge blanket reactors. The greater detail in the design parameters presented in the revision of NBR 12.209 and the sewage treatment plants with UASB reactors already in place and in operation, such as the 186 treatment plants, which together have the capacity to treat 15,366L / s, operated by four of the leading sanitation companies in Brazil, make clear how technology has finally gained ground in Brazil.
\end{abstract}

Keywords:PROSAB, NBR 12.209, Sewage treatment. 


\title{
Desarrollo de la Aplicación de los Reactores Anaeróbicos de Manta de Lodo (UASB) en Brasil
}

\begin{abstract}
Resumen:La disposición inadecuada de las aguas residuale sem el medio ambiente siempre ha sido motivo de preocupación de las sociedades em el mundo. Especialmente en países em desarrollo, los problemas de disposición y tratamiento de las aguas residuales se hacen aún más evidentes. En Brasil, el avance em los estudios e investigaciones sobre tratamiento de alcantarillas a través de sistemas anaeróbicos, especialmente los reactores de manta de lodo (UASB), se dio a partir del Proyecto PROSAB, en 1999, de donde surgieron investigaciones, artículos, libros y proyectos de diversos autores sobre el tema, convirtiéndose em referencia no sólo para La revisión em la NBR 12.209 en 2011, sino también para La implantación de varias estaciones de tratamiento de aguas residuales de diferentes tamaños y en diferentes estados, a través de sus respectivas compañías de saneamiento . Com el objetivo de analizar La evolución y buena aceptación de La tecnología UASB en Brasil, se evaluaron las alteraciones em la NBR 12.209, los principios de funcionamiento de los reactores UASB y las compañías nacionales de saneamiento que utilizan reactores UASB, fundamentales para el desarrollo y aceptación de La tecnologia em el pais. A pesar de La divergência encuanto a la nomenclatura por lãs compañías de saneamiento en Brasil, la sigla UASB sigue siendo La más difundida y utilizada em la literatura sobre los reactores de manta de lodo. El mayor detalle em los parámetros de proyecto presentados em La revisión de la NBR 12.209 y las estaciones de tratamiento de aguas residuales com reactores UASB ya implantadas y em operación, a ejemplo de las 186 estaciones de tratamiento, que juntas tienen capacidad de tratar $15.366 \mathrm{~L} / \mathrm{s}$, operadas por cuatro de lãs principales compañías de saneamiento en Brasil, dejan claro cómo la tecnologia ganó espacio en definitiva en Brasil.
\end{abstract}

Palabras clave:PROSAB, NBR 12.209, Tratamiento de aguas residuales.

\section{INTRODUÇÃo}

Segundo Metcalf e Eddy (2016), o objetivo inicial do uso dos processos anaeróbios foi a liquefação dos sólidos presentes nos esgotos, para reduzir ou eliminar a necessidade de gerenciamento dos mesmos e tornar o efluente adequado para um tratamento subsequente, ou para a utilização na agricultura. Os primeiros passos no desenvolvimento das tecnologias de tratamento anaeróbio datam da segunda metade do século XIX, onde se pode citar o digestor automático de Mouras, o tanque Dortmund e o sistema Scott-Moncrieff. Segundo os mesmos autores, o primeiro tanque séptico foi construído por Donald Cameron na Inglaterra em 1895.

Segundo Metcalf e Eddy (2016), o próximo avanço relevante na tecnologia de tratamento anaeróbio foi o tanque de Travis, quando W. 0. Travis desenvolveu um tanque com dois compartimentos para a liquefação de lodos. Em 1906, o Dr. Karl Imhoff patenteou, na Alemanha, um dispositivo de tratamento anaeróbio de efluentes com separação de sólidos da fase líquida, antes do descarte do efluente. Esse dispositivo, que ficou conhecido como tanque Imhoff, foi baseado no trabalho desenvolvido por Travis. Os tanques Imhoff ainda são utilizados nos dias de hoje. 
Desenvolvimento da Aplicação dos Reatores Anaeróbios de Manta de Lodo (UASB) no Brasil

Segundo Jordão e Pessôa (2014), o tanque Imhoff é o exemplo mais conhecido da aplicação da tecnologia anaeróbia a esgotos sanitários. No Brasil, unidades implantadas demonstraram resultados muito bons e compatíveis com o objetivo, a citar as Estações de Tratamento de Esgoto (ETEs) Torres, no Rio Grande do Sul, Realengo, no Rio de Janeiro, e Campina Grande, na Paraíba, sendo esta última já desativada.

De acordo com Metcalf e Eddy (2016), avanços relevantes na tecnologia de tratamento anaeróbio de efluentes com alta carga orgânica incluem o trabalho de Schroepfer para 0 tratamento de efluentes das atividades de embalagem de carne com processo anaeróbio de contato, o filtro anaeróbio de Young e McCarty no final da década de 1960 e o desenvolvimento do reator anaeróbio de fluxo ascendente com manta de lodo por Lettinga.

Segundo Jordão e Pessôa (2014), no final da década de 1970, o reator anaeróbio de fluxo ascendente de manta de lodo foi desenvolvido pelo Prof. GatzeLettinga e sua equipe, na Universidade de Wageningen, na Holanda. 0 reator recebeu 0 nome de UASB (UpflowAnaerobicSludgeBlanketReactor), terminologia essa adotada pelos especialistas brasileiros. No início, a tecnologia era aplicada exclusivamente a esgotos com alta concentração de Demanda Química de 0xigênio (DQ0) e Demanda Bioquímica de 0xigênio (DB0), como é o caso de despejos industriais específicos. Esgotos domésticos com baixa concentração de matéria orgânica só vieram a ter este processo aplicado com êxito a partir da metade dos anos 1990 .

Para Metcalf e Eddy (2016), a aplicação da tecnologia UASB para tratamento de efluentes domésticos pode ser uma opção atrativa, especialmente em países menos desenvolvidos e de clima quente. Segundo os mesmos autores, a primeira unidade de tratamento de grande porte com reatores do tipo UASB foi instalada em 1989 em Kanpur, na Índia, com capacidade de tratamento de $5.000 \mathrm{~m}^{3} /$ dia.

Segundo Jordão; Pessôa (2014), os reatores UASB possuem operação simples e econômica, sendo estudado e aprimorado principalmente em países em desenvolvimento, dentre eles, o Brasil.

De acordo comChernicharo (2007), em decorrência da ampliação de conhecimento na área, os sistemas anaeróbios de tratamento de esgoto, notadamente os reatores de manta de lodo (UASB) cresceram em maturidade, passando a ocupar uma posição de destaque no Brasil e 
no mundo. Essa trajetória de aceitação passou de um estágio de descrédito, até o início dos anos 80, para a fase atual de grande aceitação.

Segundo Van Lieret al., (2010), o pré-tratamento de esgotos utilizando reatores UASB oferece uma série de vantagens, como sistemas compactos, consumo de energia pouco significante, produção de lodo excedente estabilizado, potencial de recuperação de energia, acessibilidade de baixo custo de esgoto para fins de reutilização agrícola, etc...

0 Programa de Pesquisa em Saneamento Básico, financiado pela FINEP, CNPq e CEF, iniciado no final dos anos 90, foi preponderante para a disseminação no Brasil do tratamento anaeróbio através dos Reatores Anaeróbios de Fluxo Ascendente e Manta de Lodo, denominados UASB, conforme ressaltado por Costa; Barbosa Filho; Giordano (2014). 0 PROSAB, em seu tema 2 (tratamento de esgotos), financiou projetos de pesquisa direcionados diretamente aos reatores anaeróbios em 2 editais: 1) Tratamento de Esgotos Sanitários por Processo Anaeróbio e Disposição Controlada no Solo, sob a coordenação de Campos (1999); e 2) Pós-Tratamento de Efluentes de Reatores Anaeróbios, sob a coordenação de Chernicharo (2001). Os editais seguintes, ainda no tema 2, apesar de abordarem assuntos mais gerais, como reuso, fertirrigação e nutrientes, também apoiaram as pesquisas relacionadas aos reatores anaeróbios, porém de maneira indireta. Dessa forma, pode-se concluir que o PROSAB como um todo foi de grande importância para a consolidação do tratamento anaeróbio por reatores UASB no Brasil.

Segundo Miki (2010), a adoção do reator UASB no Brasil como tratamento de esgoto não apresenta viabilidade do ponto de vista legal, sendo necessária a adoção de alguma forma de pós-tratamento; 0 lodo ativado, para o autor, é uma modalidade que atende as expectativas de tratamento de nível secundário. Mesmo assim, o mesmo autor atesta que um dos principais atrativos da tecnologia UASB como a principal unidade de tratamento biológico de esgoto deve-se, principalmente, à constatação de que fração considerável do material orgânico (em geral próximo a 70\%) pode ser removida sem o dispêndio de energia ou adição de substâncias químicas auxiliares.

Atualmente, entende-se o Reator UASB como praticamente a principal tecnologia a ser adota em uma etapa primária de tratamento de esgotos, apesar de perfazer um processo biológico, em detrimento aos simples decantadores primários com eficiências bastante limitadas. 
Estudos realizados no Brasil com reatores UASB + Pós-Tratamento demonstraram bons resultados quanto à eficiência do sistema, como atestam Chernicharo; Araújo; Gonçalves (1996) em seu artigo Estudos Sobre o Pós-Tratamento de Efluentes de Reatores UASB Atravésde Biofiltros Aerados Submersos, onde acrescentam praticamente todas as análises de alternativa de tratamento incluem os reatores UASB como uma das principais opções.

Segundo Andrade Nettoet al., (2002), em Minas Gerais existem vários sistemas compostos com reatores UASB seguidos de filtro anaeróbio, construídos em ferrocimento, estando alguns deles em operação desde 1997, atendendo populações que variam de 2.000 a mais de 15.000 habitantes.

Diante de todo histórico apresentado, este trabalho teve como objetivos apresentar a evolução da tecnologia UASB no Brasil, as alterações sofridas pela NBR 12.209 e utilização prática da tecnologia pelas companhias de saneamento nacionais.

\section{MATERIAL E MÉTODOS}

0 trabalho de pesquisa sobre o desenvolvimento da tecnologia do Reator UASB foi todo desenvolvido a partir de três principais fatores, a saber:

- Alterações na NBR 12.209 - edições de 1992 e 2011: Este fator foi adotado devido à inclusão dessa tecnologia na revisão de 2011 da NBR 12.209, com seus respectivos parâmetros de dimensionamento hidráulico-sanitários. Anteriormente à revisão deste aspecto normativo, o Reator UASB não era abordado pela ABNT;

- Princípios de funcionamento dos reatores UASB: Ao longo dos anos de desenvolvimento da tecnologia, os reatores sofreram diversas modificações e alterações com objetivos diversos de ganho de desempenho, minimização de impactos com odores e evolução de critérios de dimensionamento;

Reatores UASB operados pelas companhias de saneamento no Brasil: A aceitação da implantação de reatores UASB no Brasil se deu ao longo dos anos de desenvolvimento do processo. Por se tratar de uma tecnologia anaeróbia, que possui desempenho de remoção de carga orgânica mais baixa quando comparada aos processos aeróbios, a implantação da 
tecnologia encontrou diversos entraves até o elevado nível de aceitação atual. A elucidação das vantagens em relação às desvantagens diante de experiências práticas em estações já implantadas e em operação foi de grande relevância para essa consagração da tecnologia nos dias atuais em todo o país.

\section{RESULTADOS E DISCUSSÃ0}

Os avanços e o desenvolvimento da tecnologia do Reator UASB serão discutidos à luz dos três fatores adotados para essa pesquisa e descritos no item MATERIAIS E MÉTODOS.

\section{Alterações na NBR 12.209 - edições de 1992 e 2011}

A disseminação com grande aceitação da tecnologia anaeróbia, especialmente dos reatores UASB, ocasionou mudanças na Norma NBR 12.209 em 2011. A princípio, a mudança mais clara se deu na citação aos reatores UASB, não mencionados na edição de 1992. Além disso, a edição de 1992,quando trata da tecnologia anaeróbia, apresenta-a apenas como tecnologia para o tratamento do lodo (fase sólida) e do gás gerado na digestão anaeróbia, e não do efluente líquido

A nova edição da NBR 12.209 apresenta não só os parâmetros revisados no tratamento do lodo(fase sólida) e do biogás, como também parâmetros detalhados para se projetar os reatores UASB para tratar o efluente líquido gerado. 0 lodo retirado em excesso dos reatores UASB é considerado estabilizado, podendo ser encaminhado diretamente para o deságue, sendo uma vantagem apresentada na nova edição pelo uso de reatores UASB.

As principais mudanças entre as edições de 1992 e 2011 com relação ao tratamento do lodo (fase sólida) são descritas no Quadro 1. 
Quadro 1- Resumo das modificações observadas na revisão da NBR 12.209 de 1992 para 2011 para o tratamento do lodo (fase sólida).

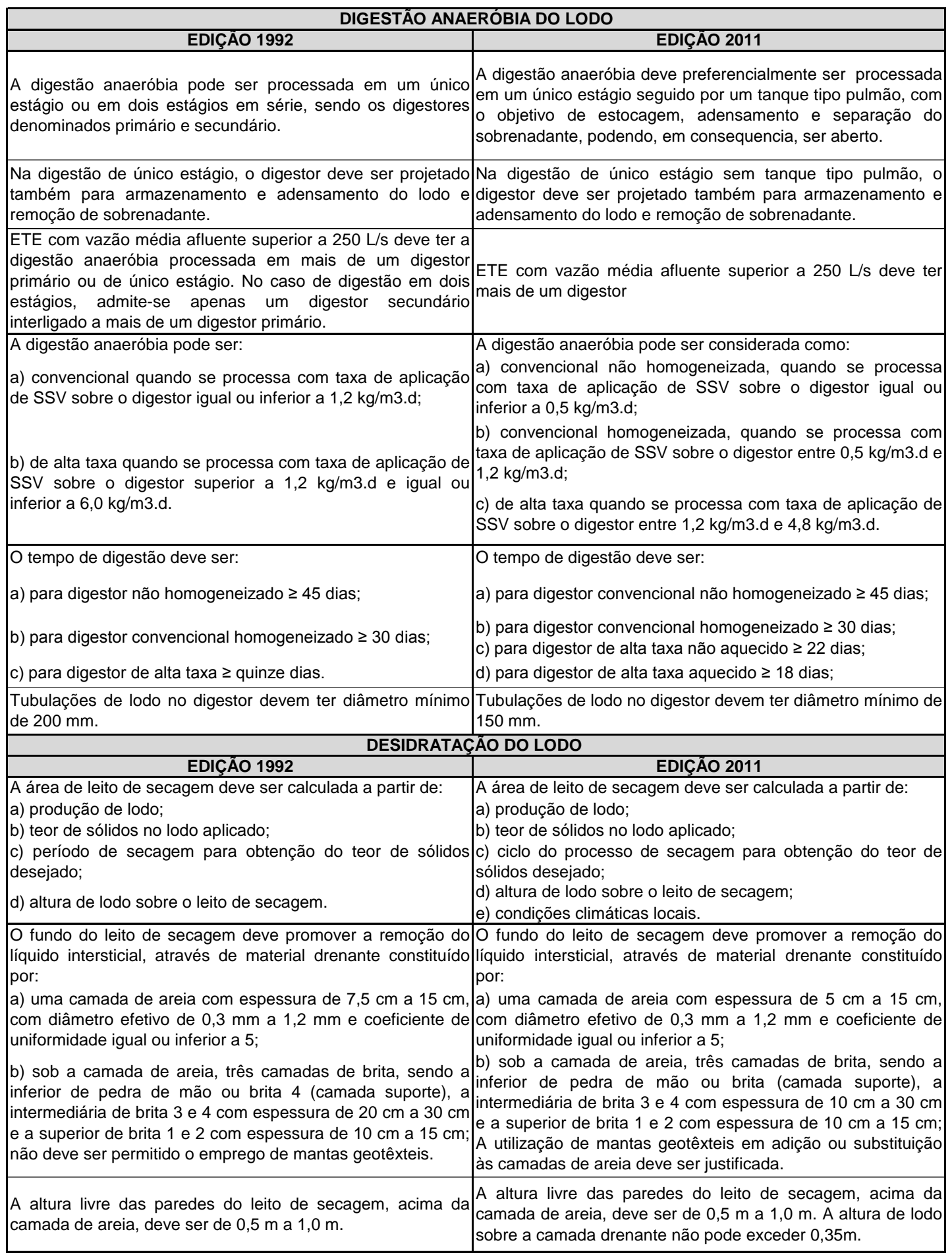

Fonte: Adaptado da NBR 12.209/92 e da NBR 12.209/11.

Outro fator importante a ser citado pela mudança na NBR 12.209 diz respeito à temperatura em que deve ocorrer a digestão anaeróbia, delimitada na faixa de 30 a $35^{\circ} \mathrm{C}$ ou na 
faixa de 50 a $57^{\circ} \mathrm{C}$. A nova edição esclarece ainda que os itens referentes à digestão anaeróbia nela contida referem-se à digestão mesofílica, entre 20 e $35^{\circ} \mathrm{C}$. Este fator é importante para se verificar a necessidade de aquecimento da unidade, prevista em ambas as edições, e garantir uma maior eficiência do tratamento. Quando o aquecimento é necessário, a nova edição, diferentemente da edição de 1992, recomenda o uso de trocadores de calor externos ao digestor.

Outros pontos importantes citados na revisão da NBR 12.209 em 2011 dizem respeito às características que os reatores devem possuir, como por exemplo, a profundidade útil total dos reatores e a profundidade mínima do compartimento de digestão.

Com relação à destinação do biogás, a revisão da Norma aprimorou as condições quando houver ou não reaproveitamento do mesmo e, diferentemente da edição de 1992, não permite o lançamento direto na atmosfera. Mesmo havendo reaproveitamento, a nova edição exige a instalação de pelo menos um queimador como unidade de segurança.0 Quadro 2 apresenta as mudanças na NBR 12.209, relacionadas ao biogás.

Quadro 2- Resumo das modificações observadas na revisão da NBR 12.209 de 1992 para 2011 relacionadas ao biogás.

\begin{tabular}{|c|c|}
\hline \multicolumn{2}{|c|}{ BIOGÁS } \\
\hline EDIÇÃO 1992 & EDIÇÃO 2011 \\
\hline \multirow{3}{*}{$\begin{array}{l}\text { No caso de digestor coberto, o gás de digestão, quando não } \\
\text { aproveitado, pode ser eliminado através de queimadores ou } \\
\text { dissipado na atmosfera sem queima, quando } \\
\text { comprovadamente não houver risco de incêndio, explosão e } \\
\text { problemas de odor, devendo a descarga se dar a uma altura } \\
\text { não inferior a 3,0 m acima do topo do digestor. }\end{array}$} & $\begin{array}{l}\text { O biogás coletado quando não aproveitado, deve ser } \\
\text { queimado, preferencialmente com queima completa. }\end{array}$ \\
\hline & $\begin{array}{l}\text { No caso de se ter o aproveitamento do biogás, deve ser } \\
\text { previsto, além das unidades próprias do aproveitamento, pelo } \\
\text { menos um queimador como unidade de segurança. }\end{array}$ \\
\hline & $\begin{array}{l}\text { Estações com capacidade acima de } 250 \mathrm{~L} / \mathrm{sde} \text { vazão média, } \\
\text { sem aproveitamento do gás, devem dispor de pelo menos } \\
\text { dois queimadores, sendo um deles reserva. }\end{array}$ \\
\hline $\begin{array}{l}\text { A tubulação de transporte do gás de digestão deve ser de } \\
\text { material resistente à corrosão, dimensionada com velocidade } \\
\text { máxima de } 4,00 \mathrm{~m} / \mathrm{s} \text {. O limite acima refere-se às tubulações } \\
\text { em que não há compressão do gás. }\end{array}$ & $\begin{array}{l}\text { As tubulações de transporte do biogás e as respectivas peças } \\
\text { especiais devem ser preferencialmente aéreas, buscando } \\
\text { manter a linearidade e o escoamento do condensado no } \\
\text { interior da tubulação, dimensionadas com velocidade máxima } \\
\text { de } 5 \mathrm{~m} / \mathrm{s} \text { em relação à vazão média do gás e diâmetro mínimo } \\
\text { de } 50 \mathrm{~mm} \text {. }\end{array}$ \\
\hline $\begin{array}{l}\text { A coleta e o transporte do gás de digestão devem dispor de } \\
\text { dispositivos de segurança, compreendendo removedores de } \\
\text { condensados, corta-chamas, reguladores de pressão e } \\
\text { limitadores de pressão máxima e subpressãodotados de } \\
\text { alarme. }\end{array}$ & $\begin{array}{l}\text { O sistema de coleta e transporte do biogás deve dispor de } \\
\text { dispositivos de segurança, compreendendo no mínimo } \\
\text { removedores de condensados e removedores de sedimentos, } \\
\text { nos pontos baixos das tubulações, válvulas de alívio de } \\
\text { pressão e vácuo, e corta-chamas. }\end{array}$ \\
\hline $\begin{array}{l}\text { É recomendada a medição da vazão do gás de digestão em } \\
\text { cada digestor. }\end{array}$ & $\begin{array}{l}\text { É recomendada a medição da vazão do biogás em cada } \\
\text { reator, devendo ser instalada com by-pass. }\end{array}$ \\
\hline
\end{tabular}

Fonte: Adaptado da NBR 12.209/92 e da NBR 12.209/11..

Os reatores UASB apresentam dois compartimentos bem definidos, sendo eles o de decantação e o de digestão. Alguns dos importantes parâmetros citados na Norma revisada são fundamentais para o funcionamento adequado de cada uma dessas câmaras e do reator 
Desenvolvimento da Aplicação dos Reatores Anaeróbios de Manta de Lodo (UASB) no Brasil

como um todo, tais como o tempo de detenção hidráulica total, que está diretamente ligado à temperatura do esgoto, profundidade útil total e da câmara de digestão, sistema de distribuição e carga orgânica volumétrica aplicada, velocidade ascensional no compartimento de digestão, taxa de escoamento superficial e tempo de detenção hidráulica no compartimento de decantação e velocidade de passagem do compartimento de digestão para o de decantação.

Os principais parâmetros de projeto de reatores UASB presentes Norma 12.209/11 são apresentados nas Tabelasl, 2 e 3.

Tabela 1- Tempo de Detenção Hidráulico e Profundidade Útil Total do Reator.

\begin{tabular}{|c|c|c|}
\hline \multicolumn{2}{|c|}{ Tempo de Detenção Hidráulico } & \multirow{2}{*}{$\begin{array}{l}\text { Profundidade Útil } \\
\text { Total do Reator }\end{array}$} \\
\hline Temperatura $\left({ }^{\circ} \mathrm{C}\right)$ & Tempo Médio (h) & \\
\hline 15 a 17 & $>=10$ & \multirow{4}{*}{ Entre $4 \mathrm{~m}$ e $6 \mathrm{~m}$} \\
\hline 18 a 21 & $>=8$ & \\
\hline 22 a 25 & $>=7$ & \\
\hline$>25$ & $>=6$ & \\
\hline
\end{tabular}

Fonte: Adaptado da NBR 12.209/11.

Para Costa et al., (2014), o tempo de detenção hidráulico é relevante por ter relação direta com a velocidade no processo de digestão anaeróbia, que está em conexo com o tamanho da unidade de tratamento. Segundo Chernicharo (2007), para esgotos domésticos sendo tratados na faixa de $20^{\circ} \mathrm{C}$, tem-se adotado tempos de detenção hidráulico da ordem de 8 a 10 horas para a vazão média. Para Jordâo e Pessôa (2014), o tempo de detenção hidráulico está, tipicamente, entre 6 e 10 horas.

Neste caso, conhecendo-se a vazão afluente do esgoto e fixando-se um tempo de detenção hidráulico de projeto, é possível calcular o volume do reator através da relação entre vazão e tempo de detenção hidráulico.

Em relação à velocidade ascensional, para Costa et al., (2014), o tipo de lodo existente e as cargas aplicadas interferem na velocidade ascensional máxima do reator.

As velocidades ascensionais para projeto e profundidade do compartimento de digestão são descritas pela NBR 12.209 (2011), conforme a Tabela 2. 
Tabela 2 - Velocidades Ascensionais em Função da Vazão e Profundidade do Compartimento de Digestão.

\begin{tabular}{|c|c|c|}
\hline \multicolumn{2}{|c|}{ Velocidade Ascensional } & $\begin{array}{c}\text { Profundidade do } \\
\text { Compartimento de } \\
\text { Digestão }\end{array}$ \\
\hline Vazão média & $\begin{array}{c}\text { Velocidade } \\
\text { Ascencional }(\mathbf{m} / \mathbf{h})\end{array}$ & Mínimo de $2,5 \mathrm{~m}$ \\
\hline Vazão Máxima & $<1,2$ & \\
\hline
\end{tabular}

Fonte: Adaptado da NBR 12.209/11.

Segundo Chernicharo (2007), a velocidade ascensional do fluxo é calculada a partir da relação entre a vazãoafluente e a seção transversal do reator, ou através da razão entre a altura e o tempo de detenção hidráulico.

Para os compartimentos de decantação, Jordão;Pessôa (2014) informa que o tempo de detenção e a taxa de aplicação superficial são os dois parâmetros que se sobressaem. Segundo os mesmos autores, o esgoto constituído de fase líquida e de sólidos em suspensão irá deslocar-se através destes compartimentos, de modo que a fase líquida verta pelas calhas de coleta, enquanto que a maior parte dos sólidos suspensos sedimentam e retornam à zona de digestão.

A Tabela 3 apresenta os parâmetros na decantação e de velocidade nas aberturas do decantador, conforme a NBR 12.209 (2011).

Tabela 3 - Principais parâmetros do compartimento de decantação dos reatores UASB.

\begin{tabular}{|c|c|c|c|c|}
\hline \multicolumn{2}{|c|}{ Parâmetros na Decantação } & $\begin{array}{c}\text { Velocidade Nas Aberturas do } \\
\text { Decantador }\end{array}$ \\
\hline Condição & $\begin{array}{c}\text { Taxa Aplic. } \\
\text { Superf. (m/h) }\end{array}$ & $\begin{array}{c}\text { Tempo de } \\
\text { Detenção (h) }\end{array}$ & Condição & $\begin{array}{c}\text { Velocidade } \\
\text { (m/h) }\end{array}$ \\
\hline Vazão média & - & $>1,5$ & Vazão média & $<2,5$ \\
\hline Vazão Máxima & $<1,2$ & $>1,0$ & Vazão Máxima & $<4,0$ \\
\hline
\end{tabular}

Fonte: Adaptado da NBR 12.209/11. 
Desenvolvimento da Aplicação dos Reatores Anaeróbios de Manta de Lodo (UASB) no Brasil

A velocidade de passagem nas aberturas de entrada do compartimento de decantação deve ser limitada aos valores da Tabela 3 , de modo que não haja arraste de sólidos na zona de digestão por velocidades excessivas.

Ainda, em relação aos principais aspectos do dimensionamento hidráulico sanitário do reator UASB, é importante ressaltar que o sistema de distribuição do afluente nessa unidade não é trivial e sua aplicação correta tem grande contribuição para 0 sucesso do seu desempenho. A NBR 12.209/2011 indica, por exemplo, uma área máxima de influência permitida para cada tubo de distribuição, no valor de $3,0 \mathrm{~m}^{2}$. Esse parâmetro leva ao cálculo preciso do número de tubos de distribuição para cada reator. Entretanto, autores como Jordão e Pessoa (2017) e Chernicharo (2007) sugerem que essa área de influência, mesmo limitada a 3,0 $\mathrm{m}^{2}$, seja substancialmente inferior em casos de carga orgânica volumétrica afluente ( $\mathrm{kg} \mathrm{DQ0} / \mathrm{m}^{3}$.dia) também reduzidas. Em casos de esgoto doméstico, é sabido que essas cargas orgânicas afluentes são geralmente reduzidas.

\section{Princípio de Funcionamento dos Reatores UASB}

Segundo Chernicharo (2007), procede-se inicialmente a inoculação do reator com quantidades suficientes de lodo anaeróbio, iniciando-se em seguida a sua alimentação em baixa taxa, no modo ascendente. Este período inicial é referido como start up ou partida do sistema, constituindo-se na fase mais importante da operação do reator. A taxa de alimentação do reator deve ser aumentada progressivamente, de acordo com o sucesso da resposta do sistema, ocorrendo, após alguns meses de operação, o desenvolvimento de um leito de lodo bastante concentrado (4 a 10\% ou seja, 40 a 100gST/L) junto ao fundo do reator.

Segundo Costa; Barbosa Filho; Giordano (2014), a movimentação suave do lodo no ambiente anaeróbio permite a sua floculação, com a formação de uma camada composta de grânulos de lodo ativado anaeróbio, por onde os efluentes sanitários atravessam quando entram no reator.Tem-se, então, uma ação dos micro-organismos anaeróbios da "Manta de Lodo"sobre a matéria orgânica nos efluentes sanitários. Após esta passagem, o líquido se direciona para uma zona de decantação existente na parte superior do reator. Enquanto o líquido é decantado em uma canaleta coletora, o lodo é sedimentado e incorporado à manta de lodo existente no fundo do reator. 0 efluente final tratado poderá, então, ser encaminhado 
para um tratamento complementar (polimento) ou mesmo ser direcionado ao corpo receptor, desde que tenha a anuência do órgão ambiental competente.

Segundo Chernicharo (2007), o sistema é automisturado pelo movimento ascendente das bolhas do biogás e do fluxo de esgoto através do reator. Com o movimento ascendente das bolhas de gás, ocorre o carreamento de lodo, sendo necessária a instalação de um separador trifásico (gases, sólidos e líquidos) na parte superior do reator, de forma a permitir a retenção e 0 retorno do lodo. A instalação do separador de gases, sólidos e líquidos é que garante o retorno do lodo e a grande capacidade de retenção de grandes quantidades de biomassa, de elevada atividade, sem a necessidade de qualquer tipo de meio suporte.

A Figura 1 apresenta um esquema típico de reatores UASB.

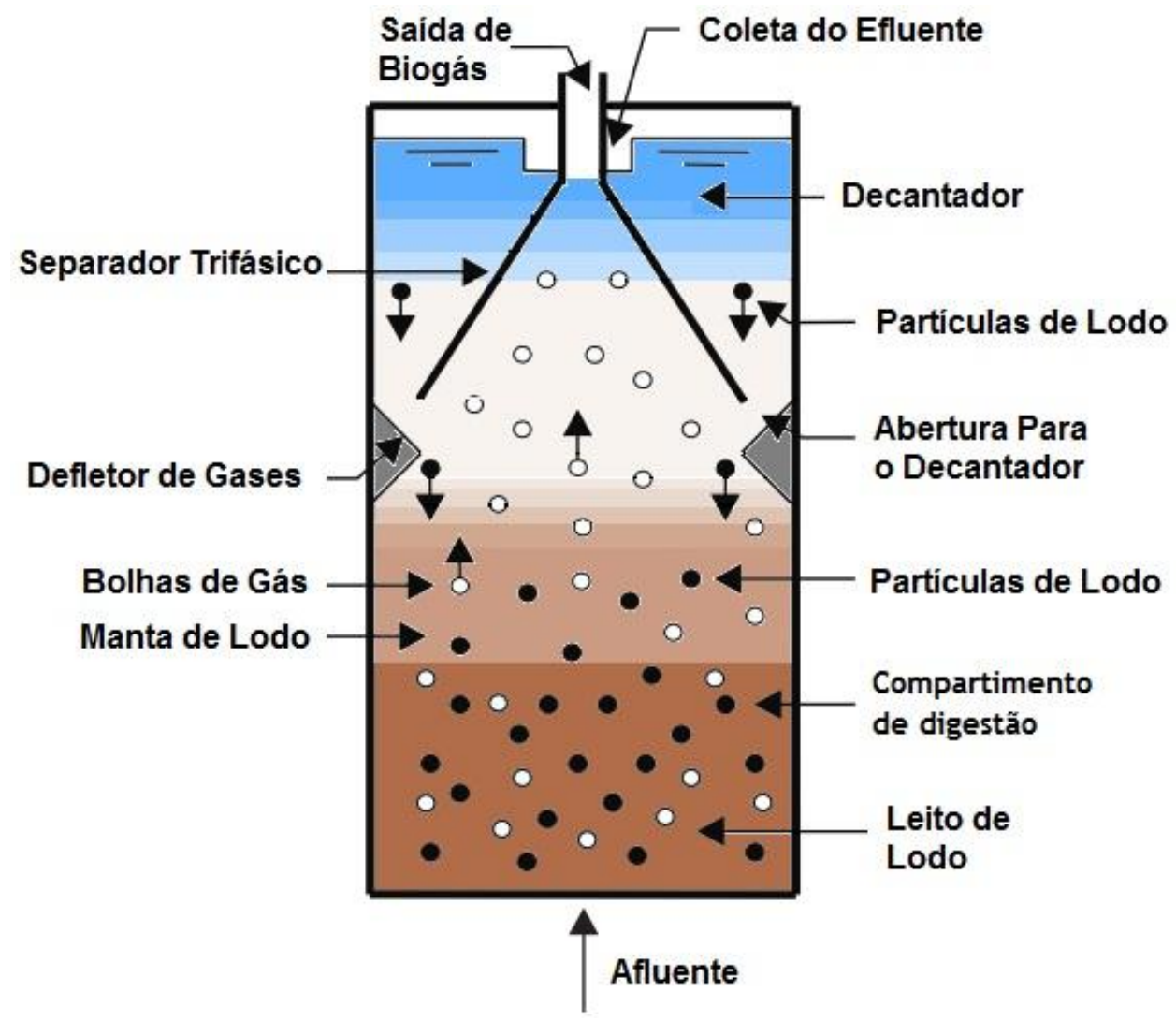

Figura 1. Esquema do processo em um reator UASB Fonte: Adaptado de Chernicharo, 2007.

De acordo com Lettinga et al., (1984), as principais condições a serem atendidas nos reatores UASB são: 
- Deve-se ter uma separação efetiva do biogás, do líquido e do lodo;

- 0 lodo anaeróbio deve atingir uma forma facilmente assentável, preferencialmente deve desenvolver-se como um lodo granular;

- 0 afluente bruto deve ser introduzido no fundo do reator, de maneira mais uniforme possível.

Para a última condição, Mara (2004) explica de forma mais clara que as águas residuais, após remoção de grãos, são distribuídas uniformemente tanto quanto possível através da base do reator, fluindo através da camada de lodo. Isso garante o contato entre as águas residuais e as bactérias anaeróbias na camada de lodo, ajudando nas reações bioquímicas anaeróbias, aumentando a eficiência na remoção de DB0 no reator.

Chernicharo (2007) adiciona às condições anteriormente citadas que os "curtoscircuitos" devem ser evitados, de forma a garantir tempos de retenção suficientes para a degradação da matéria orgânica

\section{Reatores UASB 0perados Pelas Companhias de Saneamento no Brasil}

A aceitação e disseminação da tecnologia anaeróbia para o tratamento de esgotos domésticos, notadamente os reatores tipo UASB, colocam o Brasil

em uma posição de vanguarda em nível mundial (CHERNICHAR0, 2007).

Importantes companhias de saneamento de alguns dos principais Estados brasileiros, a citar SANEPAR no Paraná, EMBASA na Bahia, COPASA em Minas Gerais, SANESUL no Mato Grosso do Sul, CESAN no Espírito Santo e CAESB no Distrito Federal, utilizam a tecnologia UASB como forma de tratamento dos esgotos gerados.

A municipal SANASA, em Campinas - SP, também utiliza reatores UASB como forma de tratamento de seus esgotos. Como apresentado por Grandin (2014), a SANASA possui diferentes sistemas de tratamento com reatores UASB + pós-tratamento, como UASB + Filtro Aerado Submerso (UASB+FAS), UASB + Lodos Ativados, UASB + Reator biológico com Leito Móvel, UASB + Tratamento Físico-Químico e UASB + Filtro biológico Percolador (UASB + FBP), de diversos portes, variando de 5 a $1200 \mathrm{~L} / \mathrm{s}$, além de apresentar as vantagens de cada sistema e um comparativo entre os sistemas de UASB + Pós-Tratamento e Lodos Ativados. 
Segundo Chernicharo (2007), a denominação de alguns tipos de reatores no Brasil é confusa. 0s reatores UASB em sua tradução para o português, deveriam se chamar Reatores Anaeróbios de Fluxo Ascendente e Manta de Lodo. No Brasil, têm sido divulgadas novas terminologias para a identificação desse tipo de reator, sendo que pelo menos quatro siglas têm sido de uso freqüente em nosso meio:

- DAFA (Digestor Anaeróbio de Fluxo Ascendente);

- RAFA (Reator Anaeróbio de Fluxo Ascendente);

- RALF (Reator Anaeróbio de Leito Fluidificado);

- RAFAALL (Reator Anaeróbio de Fluxo Ascendente Através de Leito de Lodo).

Campos (1999) cita ainda uma quinta nomenclatura para identificação desse reator, chamado de RAFAMAL (Reato Anaeróbio de Fluxo Ascendente e Manta de Lodo).

Devido à confusão causada ao público, a não contribuição para a difusão da modalidade de tratamento, a não harmonização da terminologia utilizada, além da denominação incorreta dos diferentes tipos de reatores anaeróbios, Chernicharo (2007) sugere que seja utilizada a nomenclatura original.

Nas companhias de saneamento citadas, a diferença de nomenclatura para identificação do tratamento através da tecnologia UASB é evidente. A Tabela 4 apresenta as nomenclaturas utilizadas para definição da tecnologia UASB.

Tabela 4- Nomenclatura utilizada para os reatores UASB.

\begin{tabular}{c|c}
\hline COMPANHIA & NOMENCLATURA \\
\hline CAESB & RAFA \\
\hline SANEPAR & RALF \\
\hline SANASA & UASB \\
\hline COPASA & UASB \\
\hline CESAN & RAFA \\
\hline EMBASA & DAFA \\
\hline SANESUL & UASB \\
\hline
\end{tabular}

Fonte: CAESB, SANEPAR, SANASA,COPASA, CESAN, EMBASA e SANESUL.

Alguns exemplos de estações de variados portes que utilizam reatores UASB deixam claros como a tecnologia ganhou espaço definitivamente no Brasil: 
- ETE Onça (MG): considerada a maior estação de tratamento de esgoto da América Latina a utilizar a tecnologia UASB. Para fim de projeto, a estação terá capacidade de operação para $3.600 \mathrm{~L} / \mathrm{s}$;

- Dourados ETE I Guaxinin (MS): maior estação operada pela SANESUL com reatores UASB, atendendo a uma população de 86.400 pessoas, com capacidade de 120L/s;

- ETE Parizotto (PR): opera com apenas um reator tipo RALF para uma vazão de 0,1 L/s;

- ETE Anhumas (Campinas - SP): maior estação operada pela SANASA com reatores UASB, com capacidade de $1.200 \mathrm{~L} / \mathrm{s}$;

- ETE Vale do Amanhecer (DF): estação de tratamento operada pela CAESB com reatores tipo RAFA, com capacidade de 35L/s de vazão de projeto. Atualmente, opera com vazão média de 18L/s;

De forma a exemplificar, a Tabela 5 apresenta os números divulgados das principais companhias a respeito de suas estações com tecnologia UASB.

Tabela 5- Número de estações de tratamento com tecnologia UASB e capacidade de tratamento das principais companhias de saneamento

\begin{tabular}{|c|c|}
\hline \multicolumn{2}{|c|}{ COPASA } \\
\hline № DE ETES UASB EM OPERAÇÃO & VAZÃO TOTAL (L/s) \\
\hline 122 & 9.472 \\
\hline \multicolumn{2}{|c|}{ SANASA } \\
\hline № DE ETES UASB EM OPERAÇÃO & VAZÃO TOTAL (L/s) \\
\hline \multicolumn{2}{|c|}{ CAESB } \\
\hline \multicolumn{2}{|c|}{ ' 1278} \\
\hline № DE ETES RAFA EM OPERAÇÃO & VAZÃO TOTAL MÉDIA (L/s) \\
\hline 10 SANESUL \\
\hline \multicolumn{2}{|c|}{ 2.177 } \\
\hline № DE ETES UASB EM OPERAÇÃO & VAZÃO TOTAL MÉDIA (L/s) \\
\hline 46 & 1.439 \\
\hline
\end{tabular}

Fonte: CAESB, SANASA,COPASA e SANESUL. 


\section{CONCLUSÃO}

A evolução da tecnologia anaeróbia nos últimos anos trouxe novas perspectivas no tratamento de esgotos. Atualmente, os reatores UASB se tornaram realidade no Brasil e no mundo, devido às várias vantagens apresentadas, como a remoção de cerca de $70 \%$ da matéria orgânica e a menor produção de lodo resultante de um processo anaeróbio. Por se tratar de um sistema de operação simples e econômica, torna-se uma opção viável na busca de sanar o problema de déficit do tratamento de esgoto, especialmente em países em desenvolvimento e de clima favorável, além da possibilidade do reaproveitamento do biogás produzido na geração de energia, como divulgado por Gaio (2010) em apresentação sobre o aproveitamento do potencial energético de ETEs da COPASA-MG.

Essa evolução foi sentida no Brasil após a divulgação do projeto PROSAB com o tema 2, edital 1: "Tratamento de Esgotos Sanitários por Processos Anaeróbios e por Disposição Controlada no Solo", sendo consolidado com a divulgação do edital 2: "Pós-Tratamento de Efluentes de Reatores Anaeróbios”, e com a utilização massificada desses reatores em algumas das principais companhias de saneamento do Brasil. Esses fatos foram fundamentais também para que a NBR 12.209, sobre a elaboração de projetos de estações de tratamento de esgotos, sofresse uma revisão, com maior detalhamento a respeito do tratamento anaeróbio, especialmente sobre reatores anaeróbios.

Maiores detalhamentos sobre o tratamento da fase sólida, do biogás, e a inclusão do tratamento da fase líquida na nova edição da NBR 12.209possibilitaram a execução de projetos, construções e operações mais eficientes dos reatores UASB. A ênfase dada em relação à temperatura do esgoto no tratamento anaeróbio trouxe a possibilidade de se atingir uma maior eficiência no tratamento anaeróbio, não só da fase sólida, mas também da fase líquida (impactando no tempo de detenção hidráulico do esgoto no reator), uma vez que tal condicionante, na edição de 1992, era citada apenas para o tratamento anaeróbio da fase sólida, sem maiores especificações, e da fase líquida no tratamento aeróbio.

Outro ganho relevante observado na revisão da NBR 12.209 foi à proibição da liberação do biogás (em sua maior composição sendo gás metano, combustível, 21 vezes mais impactante para o efeito estufa do que o gás carbônico e que possibilita a produção de maus odores) na atmosfera quando não houver reaproveitamento, em qualquer circunstância, bem como maiores detalhes de projeto e construção dos sistemas de coleta do biogás. A fim de 
Desenvolvimento da Aplicação dos Reatores Anaeróbios de Manta de Lodo (UASB) no Brasil

evitar danos causados aos dispositivos de coleta e transporte do biogás, a nova edição da NBR 12.209 revisou também a velocidade de escoamento no interior das tubulações.

Embora as companhias de saneamento que utilizam reatores UASB como tecnologia de tratamento utilizem diferentes nomenclaturas para definir tal tecnologia, a nomenclatura original (UASB) é a mais conhecida e, por conseqüência, a sugerida para se utilizar na definição da tecnologia.

\section{REFERÊNCIAS BIBLIOGRÁFICAS}

ABNT Associação Brasileira de Normas Técnicas. NBR 12.209: Projeto de Estações de Tratamento de Esgoto Sanitário. Rio de Janeiro, 1992.

ABNT Associação Brasileira de Normas Técnicas. NBR 12.209: Elaboração de Projetos Hidráulico-Sanitários de Estações de Tratamento de Esgotos Sanitários. Rio de Janeiro, 2011.

ANDRADE NET0, C. 0. de; VAN HAANDEL, A; MEL0, H. N. de S. 0 Usodo Filtro Anaeróbio Para Pós-Tratamentode Efluentesde Reatores Anaeróbios no Brasil. X Simpósio Luso-Brasileiro de Engenharia Sanitária e Ambiental. 2002. Braga, Portugal.

CAMPOS, J. R. Tratamento de Esgotos Sanitários por Processo Anaeróbio e Disposição Controlada no Solo. Projeto PROSAB. Rio de Janeiro: ABES, 1999. 464p.

CHERNICHAR0, C. A. de L.; ARAÚJ0, V. L.; GONÇALVES, R. F.Estudos Sobre o Pós-Tratamento de Efluentes de Reatores UASB Através de Biofiltros Aerados Submersos.Artigo Técnico, 1996.

CHERNICHAR0, C. A. de L.Pós-Tratamento de Efluentes de Reatores Anaeróbios: Coletânea de Trabalhos Técnicos. Projeto PROSAB - Volume 2. Belo Horizonte, 2001.

CHERNICHAR0, C. A. de L. Reatores Anaeróbios. Princípios do Tratamento Biológico de Águas Residuárias. Volume 5. $2^{\text {a }}$ edição. Belo Horizonte. Departamento de Engenharia Sanitária e Ambiental - DESA. Universidade Federal de Minas Gerais, 2007.

Companhia Espírito Santense de Saneamento - CESAN - ES. Disponível em: https://www.cesan.com.br. Acessado em:29 de Novembro de 2016.

Companhia de Saneamento Ambiental do Distrito Federal - CAESB - DF. Disponível em: www.caesb.df.gov.br. Acessado em: 29 de Novembro de 2016.

Companhia de Saneamento de Minas Gerais - COPASA - MG. Disponível em: www.copasa.com.br. Acessado em: 29 de Novembro de 2016.

Companhia de Saneamento do Paraná - SANEPAR - PR. Disponível em: www.sanepar.com.br. Acessado em: 29 de Novembro de 2016.

COSTA, E.S.; BARBOSA FILHO, 0.; GIORDANO, G. Reatores Anaeróbios de Manta de Lodo (UASB): Uma Abordagem Concisa. Coletânea em Saneamento Ambiental. Série Temática tecnologias Ambientais, Volume 5. $1^{\mathrm{a}}$ edição. Rio de Janeiro, 2014 
Empresa Baiana de Águas e Saneamento S.A. - EMBASA - BA. Disponível em: http://www.embasa.ba.gov.br/. Acessado em: 29 de Novembro de 2016.

Empresa de Saneamento do Mato Grosso do Sul - SANESUL - MS. Disponível em: http://www.sanesul.ms.gov.br. Acessado em: 29 de Novembro de 2016.

GAIO, M. Potencial energético das Estações de Tratamento de Esgoto. Apresentação COPASA - MG. 2010.Disponívelem:http://www.ahk.org.br/upload_arq/1Apresenta\%C3\%A7\%C3\%A30_COPASA_maio_2010_vs.pdf. Acessado em: 28 de Novembro de 2016.

GRANDIN, S. R.Tecnologias de Tratamento de Esgoto: Um Breve Comparativo. SANASA Campinas, SP.44a Assembléia Nacional da ASSEMAE. Uberlândia, MG. 04 a 09 de Maio de 2014.

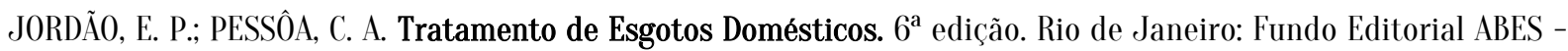
Associação Brasileira de Engenharia Sanitária e Ambiental, 2014. 969 p.

LETTINGA, G; HULSHOFF POL, L. W; KOSTER, L. W; WIEGANT, W. M; W.J. DE ZEEUW, W. J.; RINZEMA, A; GRIN, P. C; ROERSMA, R. E; HOBMA, S. W. High-Rate Anaerobic Waste-Water Treatment Using the UASB Reactor under a Wide Range of Temperature Conditions. Biotechnology and Genetic Engineering Reviews, 2:1, 253-284, 1984.

MARA, D; Domestic Wastewater Treatment In Developing Contries. Earthscan, London, 2004.

METCALF, L.; EDDY, H. P. Tratamento de Efluentes e Recuperação de Recursos. 5a edição. Porto Alegre: AMGH, 2016.

MIKI, M. K. Dilemas do UASB. Seção: Práticas operacionais e de Empreendimento.Revista DAE, n.183, p. 25-37, 2010.

SANASA - Sociedade de Abastecimento de Água e Saneamento. Campinas, São Paulo. Disponível em:http://www.sanasa.com.br/conteudo/conteud02.aspx?f=I;par_nrod=572;fla g=TS. Acessado em: 29 de Novembro de 2016.

SPERLING, M. V. Introdução à Qualidade das Águas e ao Tratamentode Esgoto. Princípios do Tratamento Biológico de Águas Residuárias. Volume 1. Departamento de Engenharia Sanitária e Ambiental - DESA. Universidade Federal de Minas Gerais. Belo Horizonte, 2005.

VAN LIER,J. B; VASHI,A; VAN DER LUBBE, J; HEFFERNAN, B. Anaerobic Sewage Treatment Using UASB Reactors: Engineering and 0perational Aspects. Environmental Anaerobic Technology: pp. 59-89. 2010. 